\title{
Exploring movement patterns of an exploited coral reef fish when tagging data are limited
}

\author{
Ashley J. Williams ${ }^{1,2, *}$, L. Richard Little ${ }^{3}$, André E. Punt ${ }^{3,4}$, Bruce D. Mapstone ${ }^{3}$, \\ Campbell R. Davies ${ }^{3}$, Michelle R. Heupel ${ }^{5}$ \\ ${ }^{1}$ Fishing and Fisheries Research Centre, School of Earth and Environment Studies, James Cook University, Townsville, \\ 4811 Queensland, Australia \\ ${ }^{2}$ Oceanic Fisheries Programme, Secretariat of the Pacific Community, BP D5, 98848 Noumea, New Caledonia \\ ${ }^{3}$ CSIRO Marine and Atmospheric Research, GPO Box 1538, Hobart, 7001 Tasmania, Australia \\ ${ }^{4}$ School of Aquatic and Fishery Sciences, Box 355020, University of Washington, Seattle, Washington 98195-5020, USA \\ ${ }^{5}$ School of Earth and Environmental Sciences, James Cook University, Townsville, 4811 Queensland, Australia
}

\begin{abstract}
Movement is one of the most fundamental demographic variables affecting the distribution and abundance of populations, but movement patterns for exploited populations of coral reef fish have not been studied extensively. Obtaining movement data for many species by means of traditional tagging methods can be difficult because of high tagging-induced mortality and low recapture rates. We used an age-structured population dynamics model parameterised using data from different regions to explore potential movement patterns for the red throat emperor Lethrinus miniatus, an exploited coral reef fish species for which traditional tagging studies have been unsuccessful. The model used a Gaussian function to describe the proportion of fish of a given age moving to or from 1 of 3 regions (Townsville, Mackay and Storm Cay) of the Great Barrier Reef. The model was fitted with and without movement to empirical age frequency data from each region over a 5 yr period (1995 to 1999). Including movement in the model led to significantly better fits to the data and revealed discrete movement patterns within each region. The model predicted net immigration to the Townsville region and net emigration from the Mackay and Storm Cay regions. We present alternative hypotheses about migration patterns of L. miniatus and highlight the importance of determining the scales at which movement in larger, exploited coral reef fishes occurs.
\end{abstract}

KEY WORDS: Movement · Coral reef fish · Lethrinus miniatus · Great Barrier Reef · Modelling · Migration · Fisheries

Resale or republication not permitted without written consent of the publisher

\section{INTRODUCTION}

Movement is one of the most fundamental demographic variables affecting the distribution and abundance of populations (Quinn \& Deriso 1999). Changes in the distribution and abundance of fish populations as a result of movement may occur over a wide range of spatial and temporal scales, including diel feeding migrations (Hobson 1973, Hall et al. 1979, Gibson et al. 1998), ontogenetic shifts in habitat type (Werner \& Hall 1988, Eggleston 1995, Ruzycki \& Wurtsbaugh 1999, Dahlgren \& Eggleston 2000), spawning migrations (Stabell 1984, Warner 1995, Bolden 2000) and move- ments in response to exploitation or other causes of density gradients (Robertson 1988, Hilborn \& Walters 1992).

The movement patterns of coral reef fishes have not been studied as extensively as they have for many temperate species. Large-scale movement of most coral reef fish species is assumed to occur only during dispersal of the pelagic larval stages (Sale 1991). Postsettlement reef fish generally are considered to be sedentary with relatively small home ranges within a reef and to move among reefs only rarely (Davies 1995, 2000, Chapman \& Kramer 2000, Meyer et al. 2007a,b). This generalisation is most probably incorrect, how- 
ever, because of the narrow range of species studied. Most studies of reef fish movement have focussed on species that have relatively small home ranges. Nevertheless, a number of studies on reef fish have demonstrated that within-reef movement of post-settlement individuals can be important in determining local population size and structure (Robertson 1988, Warner 1995, Frederick 1997, Lewis 1997). Movement patterns of potentially more mobile species of reef fish are not well known, but there is increasing evidence from tagging studies that indicate post-settlement individuals may move substantial distances within and among reefs (Holland et al. 1996, Zeller 1997, 1998, Patterson et al. 2001, Wetherbee et al. 2004). The extent to which movement is important in structuring populations of reef fish species generally remains unclear.

Recent studies of movement patterns in reef-associated fish have found that emperor (Lethrinidae) species are some of the most mobile, often moving off reefs (Kaunda-Arara \& Rose 2004a,b). Emperors generally do not appear to be territorial (Carpenter 2001) and are thought to be more mobile than reef fish in most other families (Jones 1991). Tagging studies on the Great Barrier Reef (GBR) generally have been unsuccessful at tracing movements of emperor species, such as the red throat emperor Lethrinus miniatus (Brown et al. 1994), because of very low recapture rates. The largest tagging program for $L$. miniatus on the GBR has been coordinated by the Australian National Sportfishing Association (ANSA) in Queensland, Australia, which tagged and released over 1500 L. miniatus over a period of nearly $20 \mathrm{yr}$. Only 24 of these fish have been recaptured to date, of which only 6 were at liberty for more than $12 \mathrm{mo}$. The majority of the short-term recaptures ( $<12 \mathrm{mo})$ were from the same reef on which the tagged individuals were first caught and released, but 5 of the 6 long-term recaptures were from different reefs to those at which the fish were released, with 2 fish moving around $200 \mathrm{~km}$ in a generally northerly direction across the relatively deep (80 to $130 \mathrm{~m}$ ) and sandy Capricorn Channel (B. Sawynok unpubl. data).

Movement is perhaps one of the most challenging demographic parameters to quantify for marine fishes. Conventional tagging studies are typically difficult to implement over a large spatial scale and provide limited information if recaptures are few. It is possible, however, to explore the extent of potential movement within a population by examining changes in age frequency distributions when there is a migration component to movement among local populations. The disappearance of fish from a local population can only result from mortality, net emigration or both. Net immigration or emigration to local populations can be estimated from differences between observed age fre- quency distributions and those expected in the absence of migration. Williams et al. (2007a) used catch curve analyses to estimate rates of mortality for Lethrinus miniatus on the GBR. Their estimates varied substantially among 3 regions and ranged from 0.43 to $1.06 \mathrm{yr}^{-1}$. Estimates of natural mortality for other relatively large reef fishes with similar longevities (ca. $20 \mathrm{yr}$ ) typically range between 0.1 and $0.5 \mathrm{yr}^{-1}$ (Munro \& Williams 1985, Russ et al. 1998, Newman et al. 2000a,b, Kritzer 2002). The magnitude and large variability in mortality estimates for L. miniatus suggest that movement to or from reefs in each region may have biased estimates of mortality by Williams et al. (2007a), particularly if net movement was directional or age-specific. We report here a modelling approach to exploring the magnitude and direction of potential movement of $L$. miniatus required to explain the regional variation in mortality demonstrated by Williams et al. (2007a).

\section{MATERIALS AND METHODS}

Study species. Lethrinus miniatus is a generalist predator consuming a wide range of fishes and invertebrates (Walker 1978) and is one of the largest emperor species, attaining a maximum fork length (FL) of around $600 \mathrm{~mm}$ (Williams et al. 2003, 2007b). L. miniatus generally inhabits coral reefs (Carpenter 2001) but also is encountered commonly on deeper shoal areas between reefs to depths of more than $100 \mathrm{~m}$ (Newman \& Williams 1996). The distribution of L. miniatus is restricted compared with other emperor species, with populations found only in waters around Australia, New Caledonia, Norfolk Island and the Ryuku Islands of southern Japan (Carpenter 2001). The largest populations of L. miniatus are found along the east coast of Queensland on the GBR between approximately 17.5 and $24.5^{\circ} \mathrm{S}$, where it is one of the most important commercial and recreational species in the coral reef finfish fishery (Mapstone et al. 1996, 2004, Williams 2002).

Data source. Samples of Lethrinus miniatus were collected between 1995 and 1999 from research line fishing catch surveys for the Effects of Line Fishing (ELF) experiment (Mapstone et al. 2004) implemented by the Cooperative Research Centre for the Great Barrier Reef World Heritage Area (CRC Reef). The sampling design of the ELF experiment included clusters of 6 reefs within each of 4 geographic regions of the GBR: Lizard Island, $\sim 14.5^{\circ} \mathrm{S}$; Townsville, $\sim 18.5^{\circ} \mathrm{S}$; Mackay, $20.5^{\circ} \mathrm{S}$; and Storm Cay, $\sim 12.5^{\circ} \mathrm{S}$ (Fig. 1). $L$. miniatus is encountered only rarely north of Cairns $\left(17^{\circ} \mathrm{S}\right)$ on the GBR and no samples were collected from the Lizard Island region. Reefs within each region 


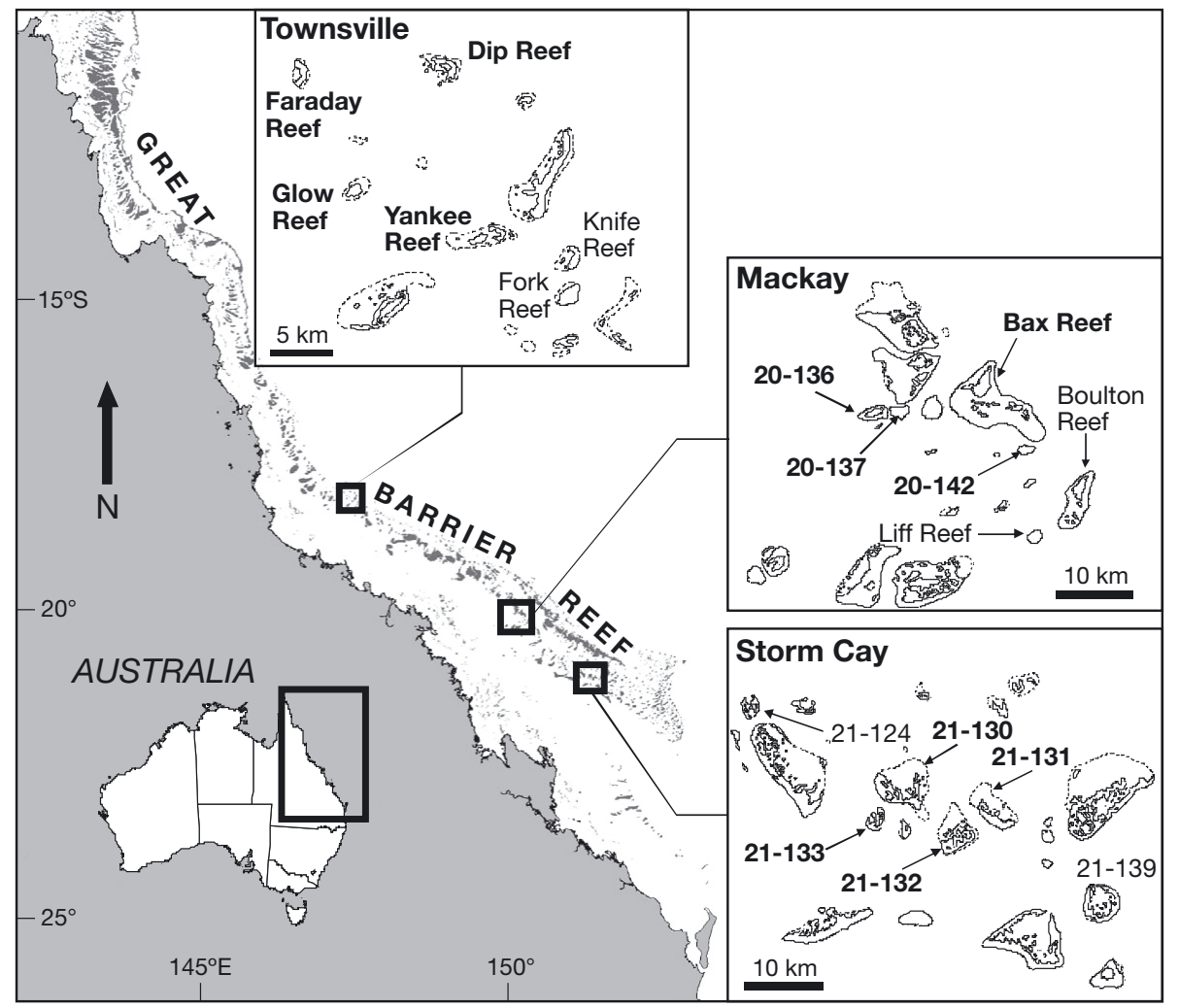

Fig. 1. Lethrinus miniatus. Location of reefs (either named or numbered) sampled within 3 regions of the Great Barrier Reef as part of the Effects of Line Fishing Experiment. Reefs in bold text were closed to fishing and were those from which samples were used for this study

were separated by less than $10 \mathrm{~km}$ and regions were separated by more than $100 \mathrm{~km}$. In each region 4 of the 6 reefs had been closed to all forms of fishing for 10 to $12 \mathrm{yr}$ before 1995. The remaining 2 reefs in each region were open to fishing historically.

Each reef was sampled for $1 \mathrm{~d}$ between September and December in each year by 4 commercial line fishers using standardised line fishing gear consisting of size 8/0 hooks, $36 \mathrm{~kg}$ breaking strain monofilament line and pilchard Sardinops neopilchardus as bait. Each fisher operated under the supervision of a researcher and sampling effort was kept constant among reefs by dividing the perimeter of each reef into 6 approximately equal size 'blocks' and distributing fishing effort evenly among blocks and across 2 depth strata $(<12 \mathrm{~m}, 12$ to $40 \mathrm{~m})$ within each block.

Otoliths were extracted from all samples and counts of opaque increments in whole otoliths, validated as annuli by Williams et al. (2005), were used to estimate ages of Lethrinus miniatus following the procedures outlined by Williams et al. (2003). Only age data from reefs closed to fishing were used in this study, as the effects of fishing were assumed to have biased the age distributions derived from reefs open to fishing. Age data were available from a total of 2410 L. miniatus individuals collected across 5 yr from 4 reefs closed to fishing in each of the 3 regions where L. miniatus occurred (Table 1). Age frequency data from reefs closed to fishing were pooled across reefs within each region since age structures of $L$. miniatus do not vary significantly among closed reefs within regions of the GBR (Williams et al. 2003).

Population dynamics model and its associated estimation procedure. A stochastic age-structured population dynamics model was developed to explore the extent of movement of Lethrinus miniatus that would be required to reproduce observed age structures from reefs closed to fishing within the Townsville,

Table 1. Lethrinus miniatus. Number of individuals collected from reefs closed to fishing within 3 regions of the Great Barrier Reef over 5 yr

\begin{tabular}{|cccc|}
\hline Year & Townsville & Mackay & Storm Cay \\
\hline 1995 & 190 & 272 & 194 \\
1996 & 121 & 201 & 152 \\
1997 & 157 & 128 & 117 \\
1998 & 101 & 129 & 176 \\
1999 & 77 & 202 & 193 \\
\hline
\end{tabular}


Mackay and Storm Cay regions of the GBR if natural mortality was constant among regions and ages. The number of fish in each region was assumed to be determined by stochastic recruitment, survivorship from the previous year and age-specific net movement with the equation:

$$
N_{Y, a}^{r}= \begin{cases}\mathrm{e}^{\varepsilon_{y-2}^{r}} & \text { if } \mathrm{a}=2 \\ \mathrm{e}^{\varepsilon_{y-a}^{r}} \mathrm{e}^{-M(a-2)} \prod_{a^{\prime}=2}^{a-1}\left(1+\phi_{a^{\prime}}^{r}\right) & \text { if } 2<\mathrm{a} \leq 20\end{cases}
$$

where $N_{y, a}^{r}$ is the number of fish in region $r$ at age $a$ at the start of year $y$ relative to the average number of age 2 fish, $M$ is the instantaneous rate of natural mortality across all regions, ages and years for fish aged 2 yr and older, $\phi_{a}^{r}$ is the age-specific net rate of movement of fish in region $r$ at age a ( $\phi_{a}^{r}$ may be negative [emigration] or positive [immigration]; movement is assumed to occur instantaneously at the start of the year and is modelled as a proportion of the number of fish of age $a$ in region $r$ ), and $\varepsilon_{y}^{r}$ is the random deviation in age $2 L$. miniatus abundance about its expected value for region $r$ and year $y$ (assumed to be normally distributed with mean of 0 and variance of $\tau^{2}$ for the purposes of parameter estimation).

Each region was assumed to constitute a single homogeneous population because the age structures of Lethrinus miniatus populations from reefs within each region were similar, while age structures differed substantially among regions (Williams et al. 2003, 2006, 2007a,b). Movement of post-recruits (>2 yr of age) was modelled in the form of net immigration or emigration to or from each region. The regions were not linked explicitly, however, and migration was not assumed to balance across the regions in the model domain because the reefs sampled constituted only a small fraction of the total number of reefs by area and no data were available with which to parameterise the distance-specific migration of fish among reefs. Thus, the models for each region were independent of each other, apart from parameters which were common across regions such as natural mortality $(M)$, the extent of inter-annual variation in recruitment and survey selectivity (see below).

Fishing mortality was assumed to be zero because the reefs within each region from which the data were obtained were legislated as areas closed to fishing and we could not estimate fishing mortality potentially affecting populations via exposure of fish to fishing when they were outside the closed areas. Thus, the only source of mortality experienced by the populations in each region was assumed to be natural. It was necessary to assume a common rate of $M$ across all regions (as well as ages and years) because movement is confounded with mortality within a region and it is not possible to estimate the effects of reef- and age-spe- cific mortality and movement simultaneously without such an assumption.

We assume that after recruitment the number of fish in the population that migrates each year increases with age up to a point, $\bar{a}^{r}$. At ages older than this, migration is assumed to decrease. We used a Gaussian function as a flexible way to represent this behaviour. The net proportion of fish of age a migrating to or from region $r$ each year, $\phi_{a}^{r}$, was therefore represented as:

$$
\phi_{a}^{r}=\mu^{r} \mathrm{e}^{-\left(a-\bar{a}^{r}\right)^{2} / \sigma_{r}^{2}}
$$

where $\bar{a}^{r}$ is the age at which net migration is maximal, $\sigma_{r}$ determines the extent to which the immigration (or emigration) rate varies with age and $\mu^{r}$ determines the relative amount of the cohort which is expected to immigrate (positive value) or emigrate (negative value). This function indicates that migration is highest at age $\bar{a}^{r}$.

In common with other attempts to model line fishing selectivity of Lethrinus miniatus (Little et al. 2009), survey selectivity, $S_{a}$, is assumed to be a logistic function of age and the same among regions:

$$
S_{a}=\left\{1+\exp \left[-\ln 19\left(a-a_{50}\right) /\left(a_{95}-a_{50}\right)\right]\right\}^{-1}
$$

where $a_{50}$ is the age at which fish are $50 \%$ selected and $a_{95}$ is the age at which fish are $95 \%$ selected.

The assumption that line fishing selectivity is logistic for reef fishes on the GBR has been shown by Fulton et al. (1999) and incorporated into the models used to explore management strategies for these fishes (Little et al. 2009).

The values for parameters of the model $\left(M, a_{50}, a_{95}, \underline{\bar{a}}, \underline{\sigma}, \mu, \boldsymbol{\varepsilon}\right)$ were estimated by maximising a penalized likelihood function, or equivalently minimising the negative of the logarithm of the penalized likelihood function:

$$
-\ln P=-\sum_{r} \sum_{y} \sum_{a \geq 2} Q_{y, a}^{r} \ln \hat{P}_{y, a}^{r}+\frac{1}{2 \tau^{2}} \sum_{y} \sum_{r} \varepsilon_{Y}^{r}
$$

where $Q_{y, a}^{r}$ is the number of fish sampled in region $r$ during year $y$ of age $a, \hat{P}_{y, a}^{r}$ is the model-estimate of the proportion of fish in region $r$ during year $y$ of age $a$ :

$$
\hat{P}_{y, a}^{r}=\frac{S_{a} N_{y, a}^{r}}{\sum_{a^{\prime}} S_{a^{\prime}} N_{Y, a^{\prime}}^{r}}
$$

and $\tau$ is the (assumed) inter-annual variation in yearclass strength.

The first term in Eq. (4) represents the assumption that the data are a multinomial sample from the selected population in the region (estimates of overdispersion show that the assumption of independence among ages is not invalid), while the second term in Eq. (4) represents a penalty placed on the extent to which Age 2 fish abundance can vary inter-annually. 
The value for $\tau$ cannot be estimated by minimising Eq. (4) and was assumed to be 0.6 (a value typically assumed for this parameter, Beddington \& Cooke 1983), although sensitivity to values for 0.3 and 1 was also examined. The total number of random deviation parameters, $\varepsilon_{y}^{r}$, estimated for each region was 23 (19 for the first year and 4 for the subsequent years). Although it is not easy to estimate relative abundance from relative survey data alone in general (Quinn \& Deriso 1999), we ran simulations (results not shown for reason of brevity) that demonstrated that the data provided enough information to discriminate among models with different movement hypotheses. These simulations also confirmed that, even given only 5 yr of age composition data and samples sizes equal to those on which the analyses are based, it was possible to estimate natural mortality under the assumptions that selectivity is asymptotic and natural mortality is independent of age and reef.

Scenarios and model selection. The model (Eqs. 1, 2 \& 5) was fitted separately under 2 scenarios. The first scenario (Movement) assumed that emigration and immigration occurred (i.e. the parameters of Eq. 2 were estimated). The second scenario (No movement) assumed no emigration or immigration (i.e $\mu^{r}$ was set to 0 ) and, hence, assumed that differences in age structure among regions were due solely to variation in year-class strength. A likelihood ratio test was used to compare the fits of these 2 nested models for each choice of the value for the parameter $\tau$.

\section{RESULTS}

The model provided a reasonable fit to the observed age frequency data irrespective of whether movement was assumed to occur (Fig. 2). Allowing for movement, however, led to a significantly better fit (differences in negative log-likelihood of 67.39, 114.05 and 48.67 on $9 \mathrm{df}$ for $\tau=0.6,0.3$ and 1.0, respectively, $\mathrm{p} \ll 0.001$ ). This improvement in fit is most evident in the fits to the data for Townsville (Fig. 2). For example, the Movement scenario was better able to capture the higher proportion of 6 to $10 \mathrm{yr}$ old fish relative to 2 to $5 \mathrm{yr}$ old fish in Townsville in 1998, and the influx of $4 \mathrm{yr}$ old fish in Mackay in 1997 and 1998. The sum of the absolute values of the standardised residuals were lower for most years in all regions (Fig. 3), further demonstrating the improved fit of the model when allowance for movement was made.

The Movement scenario predicted considerable net immigration of fish into the Townsville region with the highest proportion of immigrants predicted to occur between 3 and 7 yr of age (Fig. 4). In contrast, the model predicted no net immigration to the Mackay region, but considerable net emigration of fish over a wide age range from approximately 3 to $14 \mathrm{yr}$. The model also predicted some emigration in the Storm Cay region, although this was only predicted for fish of age $9 \mathrm{yr}$. Varying the value of $\tau$ had little effect on the model estimates of movement parameters (Table 2). Model estimates of $M$ and the selectivity parameters also did not vary greatly with different values of $\tau$ (Table 2 ).

The relative magnitude of predicted immigration to the Townsville region was slightly greater than the magnitude of emigration predicted from the Mackay and Storm Cay regions. This result needs to be interpreted with care, however, because the regions differ in size and because $\mu^{r}$ reflects the proportion of fish immigrating or emigrating relative to the numbers already in a region, not the absolute numbers of (net) immigrants or emigrants.

Estimated population age structures differed between the 2 scenarios, with the largest difference for the Townsville region (Fig. 5). The Movement scenario generally predicted a lower abundance of young ( 2 to $4 \mathrm{yr})$ fish and greater abundance of old $(4+\mathrm{yr})$ fish in all regions, with the magnitude of the differences much larger in the Townsville region. The former result is attributable primarily to the higher estimated value for $M$ for the No movement scenario (Table 2).

The recruitment dynamics are also an important factor affecting the abundance of $2 \mathrm{yr}$ old fish in different regions at different times. Local recruitment (at age $2 \mathrm{yr}$ ) in the Townsville region was a lower fraction (0.06) of the number of $>2$ yr old fish, averaged over 1995 to 1999, than in the Mackay (0.45) and Storm Cay (0.30) regions when there was movement among regions (Fig. 5). Care should be taken when interpreting estimates of the numbers of $2 \mathrm{yr}$ old fish on each reef because these numbers are less precisely determined than are the number of fish from year classes that have been well sampled and also rely on the accuracy of the assumption of logistic selectivity (small differences in the selectivity of 2 yr old fish could substantially change the estimates of age 2 abundance for poorly sample cohorts).

\section{DISCUSSION}

Our results suggest that movement of Lethrinus miniatus to or from regions of the GBR provides a credible and parsimonious explanation of observed regional variation in age structures if natural mortality rates do not vary among regions. Modelling migration among regions provided better fits to the observed age structures than could be obtained from an alternative hypothesis that regional variation in age structures was driven only by variation in year-class strength. In 

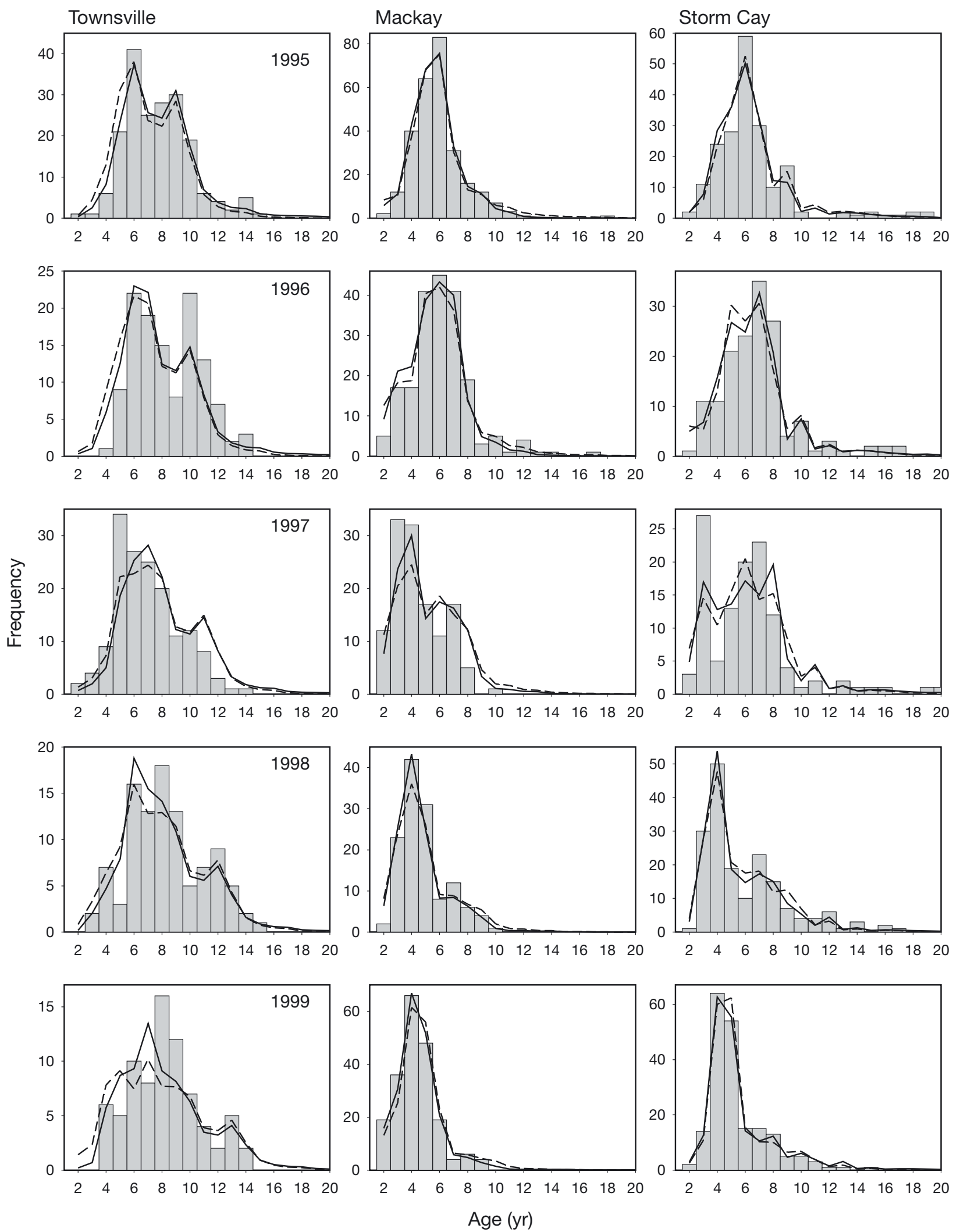

Fig. 2. Lethrinus miniatus. Fit of the 2 scenarios (solid line: Movement; dashed line: No movement) to the observed age frequency data (solid bars) for 3 regions of the Great Barrier Reef over 5 yr when the extent of variation in abundance of Age 0 fish is assumed to be 0.6 

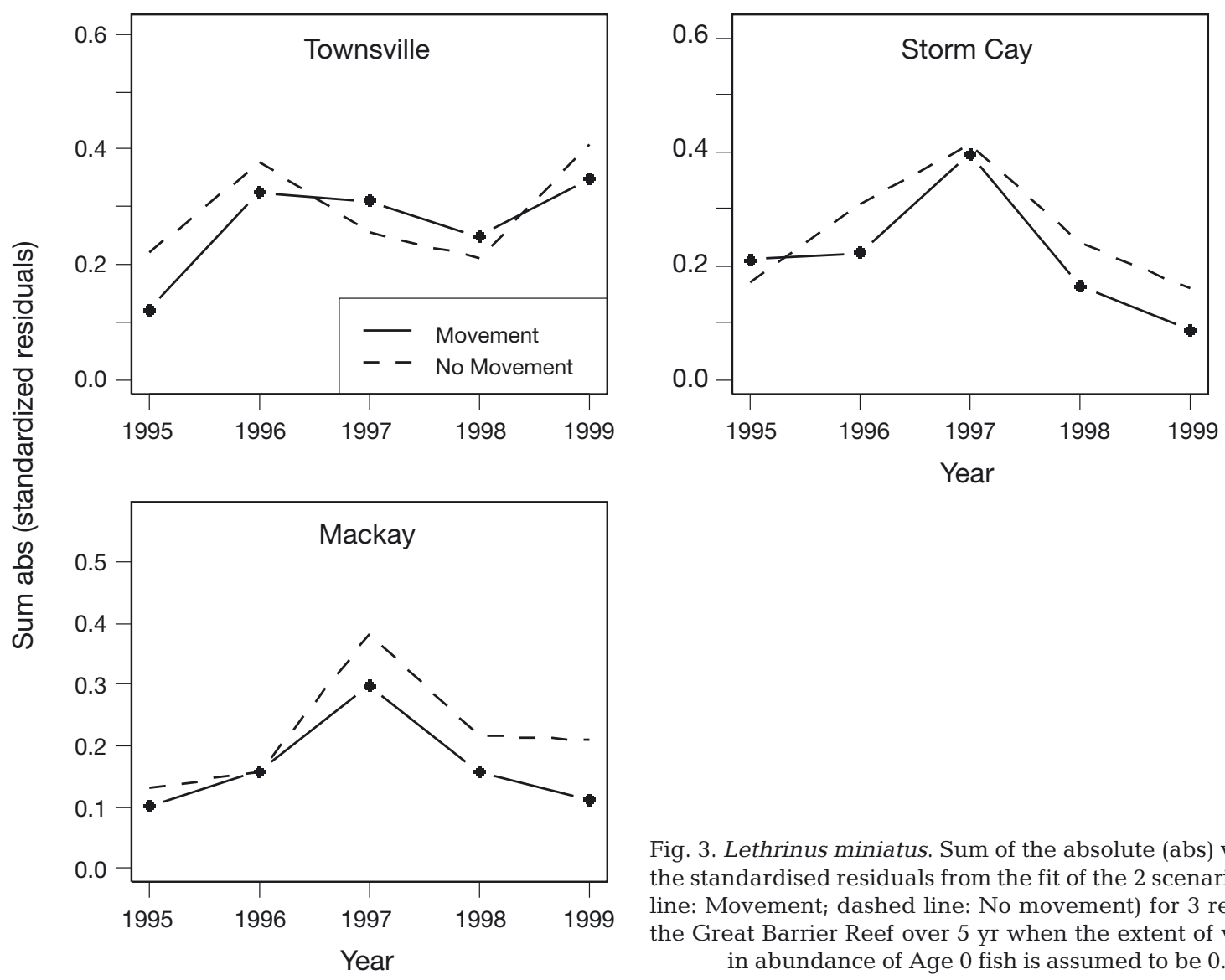

Fig. 3. Lethrinus miniatus. Sum of the absolute (abs) values of the standardised residuals from the fit of the 2 scenarios (solid line: Movement; dashed line: No movement) for 3 regions of the Great Barrier Reef over 5 yr when the extent of variation in abundance of Age 0 fish is assumed to be 0.6
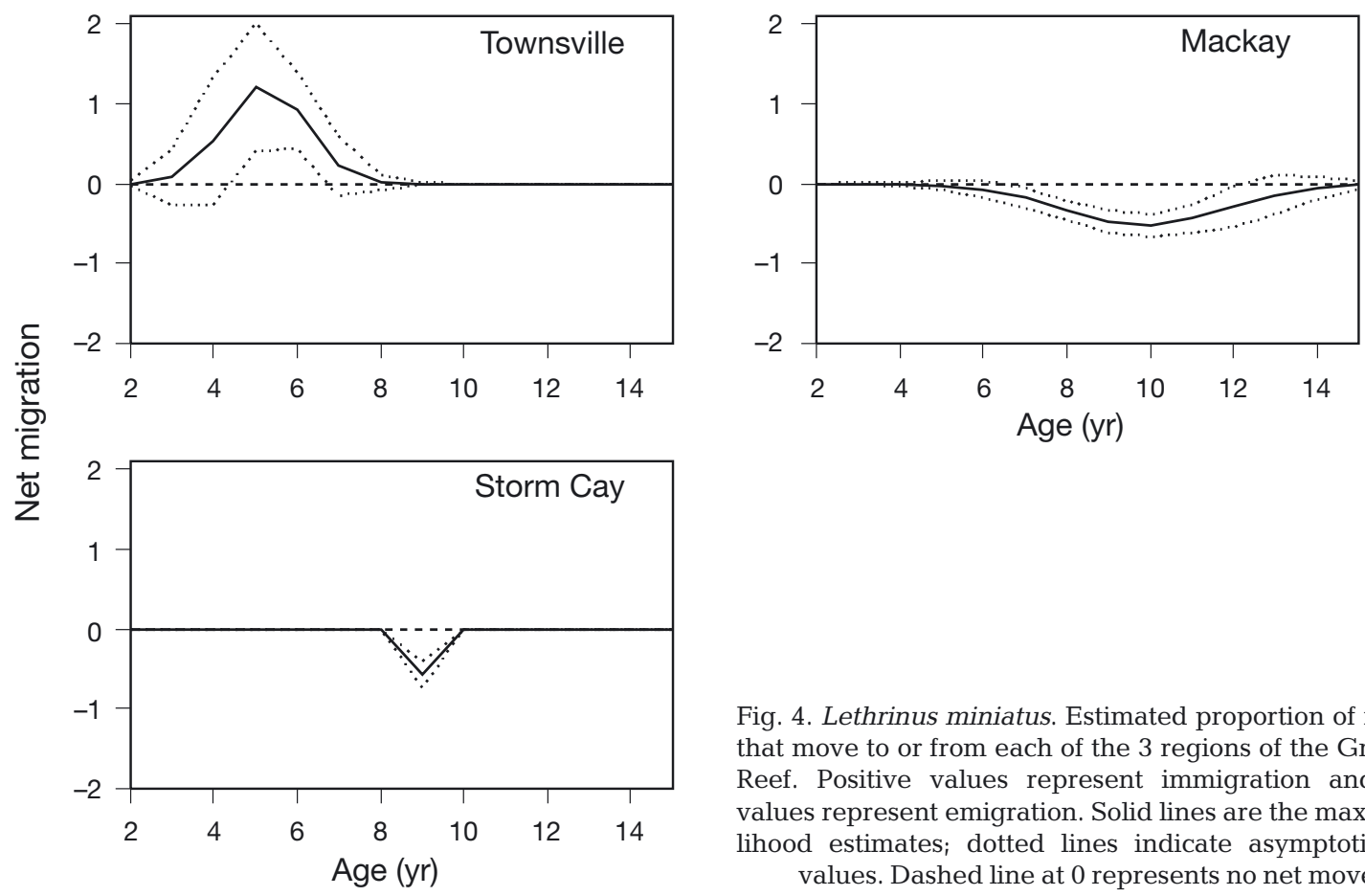

Fig. 4. Lethrinus miniatus. Estimated proportion of fish by age that move to or from each of the 3 regions of the Great Barrier Reef. Positive values represent immigration and negative values represent emigration. Solid lines are the maximum likelihood estimates; dotted lines indicate asymptotic 95\% CI values. Dashed line at 0 represents no net movement 
Table 2. Lethrinus miniatus. Estimates (with asymptotic SE values in parentheses) of the parameters of the model related to movement, natural mortality $(M)$ and selectivity. Results are shown for 3 values for the (assumed) extent of variation in recruitment $(\tau)$ and for model scenarios with and without movement. $a_{50}$ or $a_{95}$ : age at which fish are $50 \%$ or $95 \%$ selected; $\mu$ : proportion of fish expected to immigrate (positive value) or emigrate (negative value); na: not available

\begin{tabular}{|c|c|c|c|c|c|c|}
\hline \multirow{2}{*}{ Parameter } & \multicolumn{2}{|c|}{$\tau=0.6$} & \multicolumn{2}{|c|}{$\tau=0.3$} & \multicolumn{2}{|c|}{$\tau=1$} \\
\hline & No movement & Movement & No movement & Movement & No movement & Movement \\
\hline$M\left(\mathrm{yr}^{-1}\right)$ & $0.455(0.022)$ & $0.311(0.027)$ & $0.438(0.017)$ & $0.326(0.026)$ & $0.465(0.028)$ & $0.299(0.034)$ \\
\hline$a_{50}(\mathrm{yr})$ & $4.60(0.14)$ & $3.72(0.18)$ & $4.50(0.14)$ & 3.81 & $4.69(0.15)$ & $3.67(0.18)$ \\
\hline$a_{95}(\mathrm{yr})$ & $6.40(0.21)$ & $5.24(0.29)$ & $6.40(0.22)$ & $5.46(0.33)$ & $6.44(0.21)$ & $5.15(0.30)$ \\
\hline$\mu^{\text {Townsville }}$ & na & $1.25(0.43)$ & na & $1.12(0.37)$ & na & $1.30(0.45)$ \\
\hline$\mu^{\text {Mackay }}$ & na & $-0.52(0.07)$ & na & $-0.42(0.07)$ & na & $-0.59(0.08)$ \\
\hline$\mu^{\text {Storm Cay }}$ & na & $-1.00^{\mathrm{a}}(1.35)$ & na & $-1.00^{\mathrm{a}}(0.48)$ & na & $-1.00^{\mathrm{a}}(2.13)$ \\
\hline
\end{tabular}

particular, the model predicted substantial net emigration of fish from the Mackay region and net immigration to the Townsville region over a relatively wide range of age classes. The range of model estimates of $M\left(0.30\right.$ to $\left.0.47 \mathrm{yr}^{-1}\right)$ and selectivity parameters $(95 \%$ selectivity at around 6 yr of age) were consistent with the values expected for this species (Munro \& Williams 1985, Williams et al. 2003, 2007a), providing some confidence in model predictions of movement.

It is important to note that estimates of age-specific movement were expressed as a proportion of the cohort size within each region and not as a proportion of the entire population across all regions. Consequently, the absolute number of fish predicted to move in each region will be a product of the predicted proportion of fish moving and the region-specific relative abundance, and should not be expected to balance across regions. The abundance of Lethrinus miniatus is significantly greater in the Mackay region than in the Storm Cay region, which in turn is significantly greater than in the Townsville region (Mapstone et al. 2004). Thus, the absolute number of fish predicted to move may be greater than that indicated by the relative model predictions in the Townsville region and less than that predicted in the Mackay region.

\section{Implications of model assumptions}

The predictions of large-scale net movement of Lethrinus miniatus are based on a number of assumptions. A constant rate of natural mortality was assumed across regions because age- and region-specific movement and mortality are confounded otherwise, making it impossible to determine simultaneously the relative contribution of each to the loss (or gain) of individuals from populations. Estimates of $M$ reported by Williams et al. (2007a), based on the assumption of zero net movement of fish among reefs, are consistent with movements predicted here. That is, Williams et al.'s (2007a) estimates of $M$ were greatest in the Mackay region where emigration was predicted, lowest in the Townsville region where substantial immigration was predicted and intermediate in the Storm Cay region, where low levels of net movement were predicted. Nevertheless, regional variation in $M$ may have direct effects on the model predictions. For example, predicted emigration from the Mackay region may include an unknown quantity of increased natural mortality, such that $M$ is higher in this region than the common mortality rate adopted in our modelling. Similarly, a lower than predicted $M$ in the Townsville region may account for some but not all of the predicted immigration to that region.

A second assumption we made was that fishing mortality was zero. This assumption rests on 2 underpinning assumptions: (1) that there was no movement among reefs open and closed to fishing, and (2) there were no infringements of closures on the reefs from which we used data to test our models. Movement of Lethrinus miniatus among reefs, however, would result in the mixing of fish from reefs both open and closed to fishing and tend to cause overestimation of $M$ by the model since older cohorts of fish would probably have spent sufficient time on reefs open to fishing to have suffered some fishing mortality.

Finally, the net age-specific movement in the model was assumed to follow a Gaussian function. The net direction of movement across all age classes in each region predicted by the model would remain the same, however, if net age-specific movement followed a different symmetric pattern, since the deviations between the observed and predicted age frequency distributions without movement would be unchanged. 

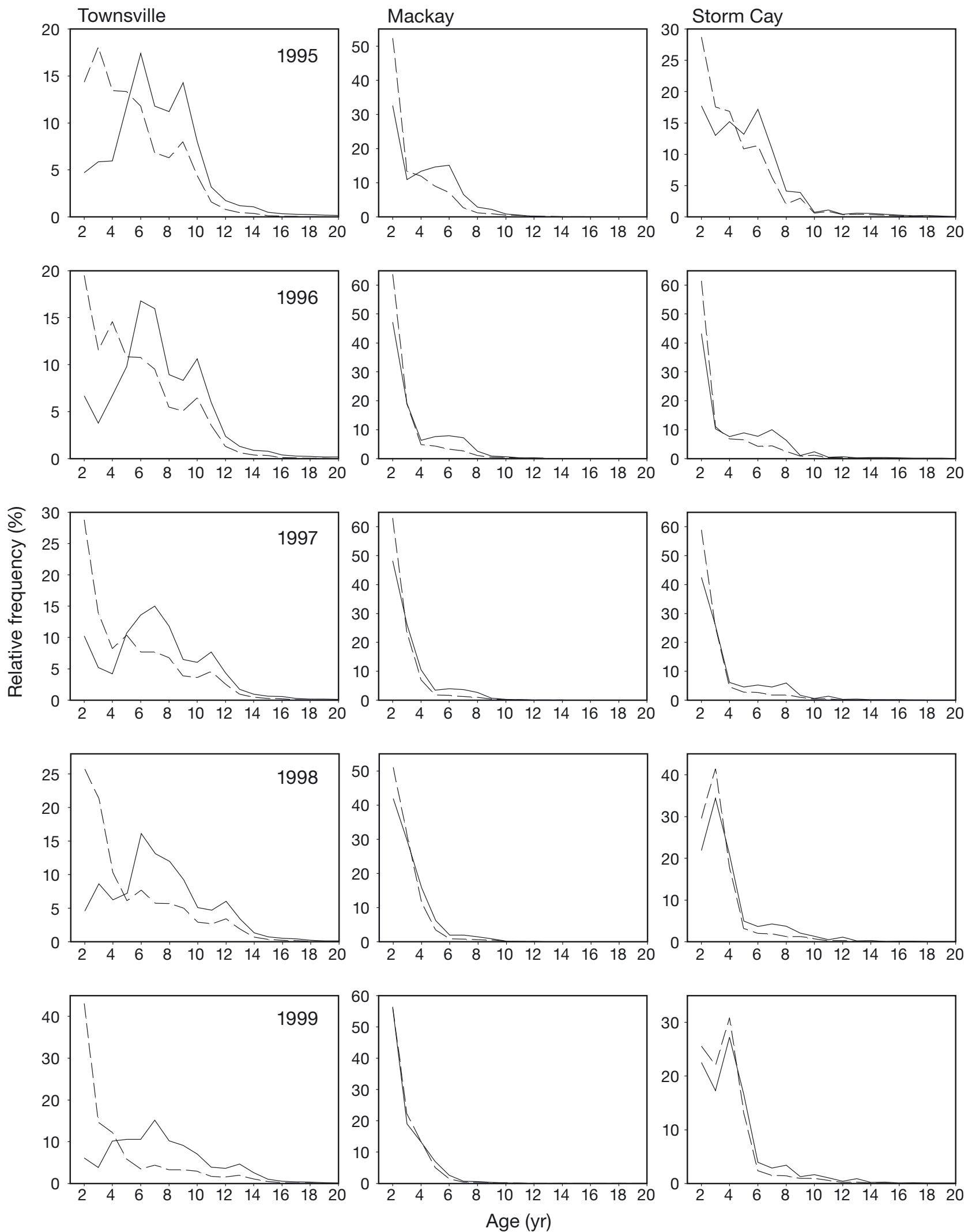

Fig. 5. Lethrinus miniatus. Estimated population age structures from the 2 scenarios (solid line: Movement; dashed line: No movement) for 3 regions of the Great Barrier Reef over 5 yr when the extent of variation in abundance of Age 0 fish is assumed to be 0.6 


\section{Potential hypotheses for movement of Lethrinus miniatus}

One hypothesis to explain the model results is that regional differences in recruitment and subsequent densities of Lethrinus miniatus result in the dispersal of post-recruits away from the centre and towards the extremes of their distribution on the GBR. The Mackay region is located approximately at the centre of the distribution of $L$. miniatus on the GBR, the Townsville region (approximately $300 \mathrm{~km}$ north of Mackay) is at the northern extreme of the distribution, and the Storm Cay region is approximately half way between Mackay and the southern extreme of the distribution (Fig. 6). Standardised catch rates (no. of fish $\mathrm{h}^{-1}$ ) of L. miniatus are greater from reefs in the Mackay region than from reefs in the Storm Cay region, which in turn are greater than those from reefs in the Townsville region (Mapstone et al. 2004). The suggested pattern of densities of $L$. miniatus is also reflected in the relative recruitment to each region predicted by the model. Larger recruitment in the Mackay region, com-

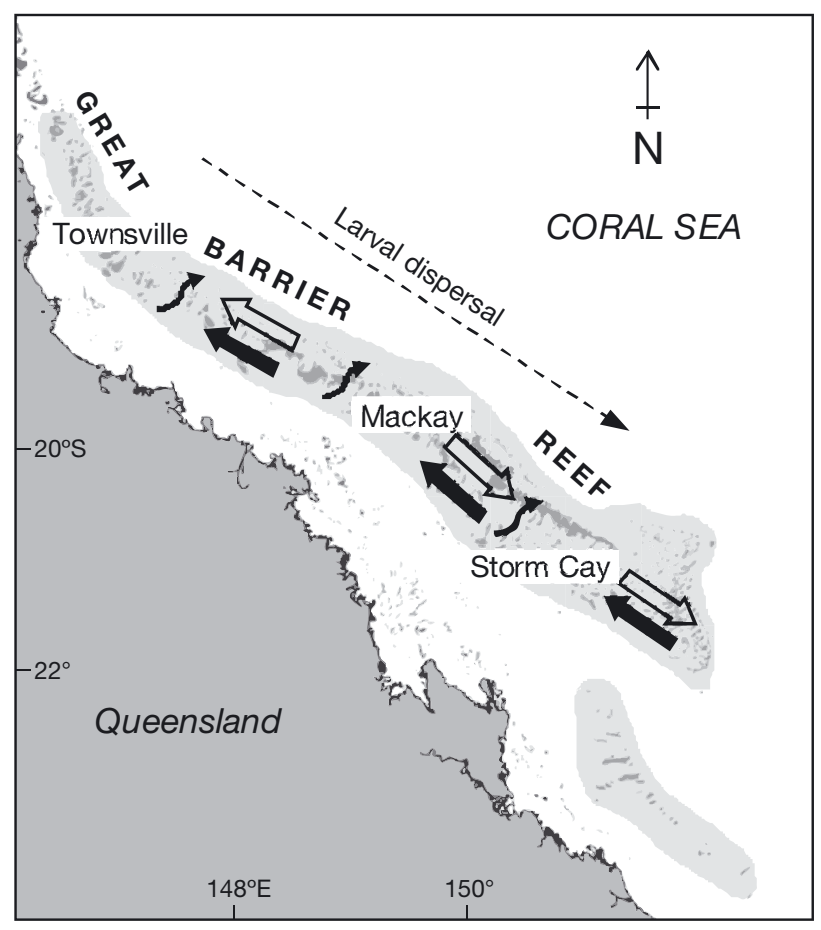

Fig. 6. Lethrinus miniatus. Hypothesised movement of postrecruits among the Townsville, Mackay and Storm Cay regions of the Great Barrier Reef (GBR). Open arrows indicate net movement for Hypothesis 1: dispersive net movement away from distribution centre. Solid arrows indicate net movement for Hypothesis 2: general northward net movement. Curved arrows indicate net movement for Hypothesis 3: cross-shelf movement. Dashed arrow indicates possible net direction of larval dispersal. Area shaded light grey indicates general distribution of $L$. miniatus on the GBR bined with net movement of fish away from the Mackay region towards the extremes of the species' range, would account for this pattern of abundance (Fig. 6), which is consistent with the net migration pattern predicted by the model. Evidence of emigration from the Storm Cay region is not consistent with this hypothesis, however, although the evidence of emigration was weak. Such large-scale post-larval dispersal has not been documented for any species of tropical reef fish although large-scale post-larval dispersal is a well-documented feature for some temperate species (e.g. Hovgård \& Christensen 1990, Frank 1992).

An alternative hypothesis is that Lethrinus miniatus has a general northerly migration on the GBR (Fig. 6). The East Australian Current generates a general southerly flow of water over the regions we considered (Church 1987, Wolanski 2001), possibly driving net southerly transport of $L$. miniatus larvae on the GBR consistent with predictions of relatively higher recruitment to the Mackay and Storm Cay regions than to the Townsville region. The proportion of $L$. miniatus that are spawning females is substantially greater in the Townsville region than in the southern regions (Williams et al. 2006), suggesting that a large proportion of L. miniatus larvae may originate from the northern end of its range on the GBR. The concept that northern regions may be major sources of larvae of several species for more southern regions on the GBR has been proposed previously (e.g. Doherty 2002, Bode et al. 2006). Net movement of post-recruit $L$. miniatus towards the northern extreme of the distribution may represent an evolutionary advantage for the species to maintain its current distribution on the GBR. Migrations to spawning sites have been documented for a number of other large reef fishes, particularly the large serranids. Some of the reported distances moved to reach a spawning site include up to $72 \mathrm{~km}$ for Epinephelus morio in the Gulf of Mexico (Moe 1969) and from 110 (Colin 1992) to $220 \mathrm{~km}$ (Bolden 2000) for $E$. striatus in the central Bahamas. The strong evidence of immigration in the Townsville region and emigration in the Mackay and Storm Cay regions is consistent with such a hypothesis for $L$. miniatus.

A final hypothesis is that net movement of Lethrinus miniatus occurs across the shelf of the GBR rather than parallel to the coastline. The cross-shelf position of the reefs we sampled differed among regions, with the Townsville reefs being farther offshore than those sampled in the Mackay and Storm Cay regions. Prediction of net immigration in the Townsville region and net emigration in the Mackay and Storm Cay regions thus would be consistent with a hypothesis of net movement of L. miniatus across the continental shelf from near-shore to off-shore reefs within regions. Such cross-shelf movements have been documented on the 
GBR for Lutjanus argentimaculatus (Russel et al. 2003) and suggested for other large lutjanids including $L$. sebae, L. malabaricus and L. erythropterus (Williams 1991, Williams \& Russ 1994). Collection of additional demographic data for $L$. miniatus across the continental shelf would be necessary to test this hypothesis.

It will be necessary to obtain direct estimates of movement from tagged or known individuals to test these hypotheses rigorously, but recapturing sufficient numbers of tagged fish to do so has proved difficult to date. Brown et al. (1994) tagged and released 667 Lethrinus miniatus in a single region of the GBR and received only 1 return in 5 yr. The lack of recaptures was attributed to the dispersal of $L$. miniatus into deeper water away from the reefs on which they were released and where most fishing is targeted. Recent advances in electronic tagging, such as acoustic telemetry, may provide an alternative tool for tracking movements in fish species that have low recapture rates. Application of this and other technologies should be considered to address these questions.

\section{Implications of large-scale movement}

Movement of Lethrinus miniatus among reefs on the GBR almost certainly occurs, although the exact magnitude and spatial scale over which it occurs is uncertain. Relatively large-scale movement has important implications for the spatial scales over which demographic processes operate. Lewis (1997) demonstrated that post-settlement movement of numerous reef fish species among patch reefs (small discrete areas $<300 \mathrm{~m}^{2}$ surrounded by sand) separated by at least $100 \mathrm{~m}$ within an individual reef significantly affected the size of populations on isolated patch reefs, thus masking variability in recruitment. Frederick (1997) found that post-settlement movement of several reef fish species among patch reefs on a similar spatial scale biased estimates of mortality when movement was ignored. It will be important to quantify recruitment, mortality and movement rates over larger spatial scales (Jones 1991), such as clusters of reefs or regions, to derive reliable estimates of population dynamics for more apparently mobile species such as L. miniatus.

We have demonstrated through use of an age-structured model that significant movement of Lethrinus miniatus among regions across hundreds of kilometres is a credible and parsimonious explanation for observed regional patterns in age structures and estimates of $M$ derived from catch curves. Movement of adult fish can decouple the relationship between demographic processes, such as recruitment and mortality, from the size of local populations. The modelling method applied here provides a starting point from which to unravel confounded demographic processes, such as movement and mortality, that cannot be inferred simultaneously from simple descriptions of population structure when empirical estimates of one of those processes (in this case movement) are limited or absent.

Acknowledgements. Funding for this research was provided by the Cooperative Research Centre for the Great Barrier Reef World Heritage Area (CRC Reef), the Fisheries Research and Development Corporation and the Great Barrier Reef Marine Park Authority. A.J.W. was supported by an Australian Postgraduate Award. We thank B. Sawynok for provision of SUNTAG tagging data and R. Stewart, M. Petersen, the crew of the 'Peri' and members of the Effects of Line Fishing (ELF) team for assistance with field work. The comments of 3 anonymous reviewers improved the manuscript and are acknowledged. This publication is a contribution from the CRC Reef Effects of Line Fishing Project.

\section{LITERATURE CITED}

Beddington JR, Cooke JG (1983) The potential yield of fish stocks. Fish Tech Pap No. 242. FAO, Rome

> Bode M, Bode L, Armsworth PR (2006) Larval dispersal reveals regional sources and sinks in the Great Barrier Reef. Mar Ecol Prog Ser 308:17-25

Bolden SK (2000) Long-distance movement of a Nassau grouper (Epinephelus striatus) to a spawning aggregation in the Central Bahamas. Fish Bull 98:642-645

Brown IW, Doherty P, Ferreira B, Keenan C and others (1994) Growth, reproduction and recruitment of Great Barrier Reef food fish stocks. Final Report, Project No. 90/18. Fisheries Research and Development Corporation, Deakin, ACT

Carpenter KE (2001) Lethrinidae. Emperor (emperor snappers). In: Carpenter KE, Niem V (eds) FAO species identification guide for fishery purposes. The living marine resources of the western Central Pacific, Vol 5. Bony fishes, Part 3 (Menidae to Pomacentridae). FAO, Rome, p 3004-3050

Chapman MR, Kramer DL (2000) Movements of fishes within and among fringing coral reefs in Barbados. Environ Biol Fishes 57:11-24

Church JA (1987) East Australian current adjacent to the Great Barrier Reef. Aust J Mar Freshw Res 38:671-683

Colin PL (1992) Reproduction of the Nassau grouper, Epinephelus striatus (Pisces: Serranidae) and its relationship to environmental conditions. Environ Biol Fishes 34: $357-377$

Dahlgren CP, Eggleston DB (2000) Ecological processes underlying ontogenetic habitat shifts in a coral reef fish. Ecology 81:2227-2240

Davies CR (1995) Patterns of movement of three species of coral reef fish on the Great Barrier Reef. PhD thesis, James Cook University, Townsville, QLD

Davies CR (2000) Inter-reef movement of the common coral trout, Plectropomus leopardus. A report to the Great Barrier Reef Marine Park Authority. Great Barrier Reef Marine Park Authority Res Publ No. 61, Townsville, QLD

Doherty PJ (2002) Variable replenishment and the dynamics of reef fish. In: Sale PF (ed) Coral reef fishes. Dynamics and diversity in a complex ecosystem. Academic Press, London, p 327-355 
Eggleston DB (1995) Recruitment of Nassau grouper Epinephelus striatus: post-settlement abundance, microhabitat features, and ontogenetic habitat shifts. Mar Ecol Prog Ser 124:9-22

Frank KT (1992) Demographic consequences of age-specific dispersal in marine fish populations. Can J Fish Aquat Sci 49:2222-2231

Frederick JL (1997) Post-settlement movement of coral reef fishes and bias in survival estimates. Mar Ecol Prog Ser 150:65-74

Fulton EA, Kault D, Mapstone BD, Sheaves M (1999) Spawning season influences on commercial catch rates: computer simulation and Plectropomus leopardus, a case in point. Can J Fish Aquat Sci 56:1096-1108

Gibson RN, Pihl L, Burrows MT, Modin J, Wennhage H, Nickell LA (1998) Diel movements of juvenile plaice Pleuronectes platessa in relation to predators, competitors, food availability and abiotic factors on a microtidal nursery ground. Mar Ecol Prog Ser 165:145-159

Hall DJ, Werner EE, Gilliam JF, Mittelbach GG and others (1979) Diel foraging behavior and prey selection in the golden shiner (Notemigonus crysoleucas). J Fish Res Board Can 36:1029-1039

Hilborn R, Walters C (1992) Quantitative fisheries stock assessment: choice dynamics and uncertainty. Chapman \& Hall, New York, NY

- Hobson ES (1973) Diel feeding migrations in coral reef fishes. Helgol Wiss Meeresunters 24:361-370

> Holland KN, Lowe CG, Wetherbee BM (1996) Movements and dispersal patterns of blue trevally (Caranx melampygus) in a fisheries conservation zone. Fish Res 25:279-292

Hovgård H, Christensen S (1990) Population structure and migration patterns of Atlantic cod (Gadus morhua) in West Greenland waters based on tagging experiments from 1946 to 1964. NW Atl Fish Org (NAFO) Sci Counc Stud 14:45-50

Jones GP (1991) Postrecruitment processes in the ecology of coral reef fish populations: a multifactorial perspective. In: Sale PF (ed) The ecology of fishes on coral reefs. Academic Press, San Diego, CA, p 294-328

Kaunda-Arara B, Rose GA (2004a) Out-migration of tagged fishes from marine reef National Parks to fisheries in coastal Kenya. Environ Biol Fishes 70:363-372

Kaunda-Arara B, Rose GA (2004b) Long-distance movements of coral reef fishes. Coral Reefs 23:410-412

Kritzer JP (2002) Variation in the population biology of stripey bass Lutjanus carponotatus within and between two island groups on the Great Barrier Reef. Mar Ecol Prog Ser 243: 191-207

Lewis AR (1997) Recruitment and post-recruit immigration affect the local population size of coral reef fishes. Coral Reefs 16:139-149

Little LR, Punt AE, Mapstone BD, Begg GA, Goldman B, Ellis N (2009) Different responses to area closures and effort controls for sedentary and migratory harvested species in a multispecies coral reef linefishery. ICES J Mar Sci 66: 1931-1941

Mapstone BD, McKinlay JP, Davies CR (1996) A description of the commercial reef line fishery logbook data held by the Queensland Fisheries Management Authority. Report to the Queensland Fisheries Management Authority, Brisbane, QLD

Mapstone BD, Davies CR, Little LR, Punt AE and others (2004) The effects of line fishing on the Great Barrier Reef and evaluation of alternative potential management strategies. Fisheries Research and Development Corporation Final Report, Project No. 97/124. CRC Reef Research Centre, Townsville, QLD
Meyer CG, Holland KN, Papastamatiou YP (2007a) Seasonal and diel movements of giant trevally Caranx ignobilis at remote Hawaiian atolls: implications for the design of Marine Protected Areas. Mar Ecol Prog Ser 333:13-25

Meyer CG, Papastamatiou YP, Holland KN (2007b) Seasonal, diel, and tidal movements of green jobfish (Aprion virescens, Lutjanidae) at remote Hawaiian atolls: implications for marine protected area design. Mar Biol 151: 2133-2143

Moe MA Jr (1969) Biology of the red grouper Epinephelus morio (Valenciennes) from the eastern Gulf of Mexico. Mar Lab Prof Pap Ser No. 10. Florida Dep Nat Resour, St. Petersburg, FL

Munro JL, Williams DMcB (1985) Assessment and management of coral reef fisheries: biological, environmental and socio-economic aspects. Proc 5th Int Coral Reef Congr Symp, Tahiti 4:545-578

> Newman SJ, Williams DMcB (1996) Variation in reef associated assemblages of the Lutjanidae and Lethrinidae at different distances offshore in the central Great Barrier Reef. Environ Biol Fishes 46:123-138

> Newman SJ, Cappo M, Williams DMcB (2000a) Age, growth, mortality rates and corresponding yield estimates using otoliths of the tropical red snappers, Lutjanus erythropterus, L. malabaricus and L. sebae, from the central Great Barrier Reef. Fish Res 48:1-14

Newman SJ, Cappo M, Williams DMcB (2000b) Age, growth and mortality of the stripey, Lutjanus carponotatus (Richardson) and the brown-stripe snapper, L. vitta (Quoy and Gaimard) from the central Great Barrier Reef, Australia. Fish Res 48:263-275

> Patterson WF III, Watterson JC, Shipp RL, Cowen JH Jr (2001) Movement of tagged red snapper in the northern Gulf of Mexico. Trans Am Fish Soc 130:533-545

Quinn TJ, Deriso RB (1999) Quantitative fish dynamics. Oxford University Press, London

- Robertson DR (1988) Abundances of surgeonfishes on patchreefs in Caribbean Panamá: due to settlement, or postsettlement events? Mar Biol 97:495-501

Russ GR, Lou DC, Higgs JB, Ferreira BP (1998) Mortality rate of a cohort of the coral trout, Plectropomus leopardus, in zones of the Great Barrier Reef Marine Park closed to fishing. Mar Freshw Res 49:507-511

Russel DJ, McDougall AJ, Fletcher AS, Ovenden JR, Street R (2003) Biology, management and genetic stock structure of mangrove jack (Lutjanus argentimaculatus) in Australia. Fisheries Research Development Corporation Final Report Project No. 1999/122. Department of Primary Industries, Northern Fisheries Centre, Cairns, QLD

Ruzycki JR, Wurtsbaugh WA (1999) Ontogenetic habitat shifts of juvenile Bear Lake sculpin. Trans Am Fish Soc 128:1201-1212

Sale PF (1991) Introduction. In: Sale PF (ed) The ecology of fishes on coral reefs. Academic Press, San Diego, CA, p 3-25

> Stabell OB (1984) Homing and olfaction in salmonids: a critical review with special reference to the Atlantic salmon. Biol Rev Camb Philos Soc 59:333-388

Walker MH (1978) Food and feeding habits of Lethrinus chrysostomus Richardson (Pisces: Perciformes) and other lethrinids in the Great Barrier Reef. Aust J Mar Freshw Res 29:623-630

Warner RR (1995) Large mating aggregations and daily longdistance spawning migrations in the bluehead wrasse, Thalassoma bifasciatum. Environ Biol Fishes 44:337-345

Werner EE, Hall DJ (1988) Ontogenetic habitat shifts in bluegill: the foraging rate-predation risk trade-off. Ecology 69:1352-1366 
Wetherbee BM, Holland KN, Meyer CG, Lowe CG (2004) Use of a marine reserve in Kaneohe Bay, Hawaii by the giant trevally, Caranx ignobilis. Fish Res 67:253-263

Williams DMcB (1991) Patterns and process in the distribution of coral reef fishes. In: Sale PF (ed) The ecology of fishes on coral reefs. Academic Press, San Diego, CA, p 437-474

Williams LE (2002) Queensland's fisheries resources: current conditions and recent trends 1988-2000. Queensland Department of Primary Industries, Brisbane, QLD

Williams DMcB, Russ GR (1994) Review of data on fishes of commercial and recreational fishing interest on the Great Barrier Reef. Report to the Great Barrier Reef Marine Park Authority, Townsville, QLD

Williams AJ, Davies CR, Mapstone BD, Russ GR (2003) Scales of spatial variation in demography of a large coral reef fish: an exception to the typical model? Fish Bull 101:673-683

Williams AJ, Davies CR, Mapstone BD (2005) Variation in the periodicity and timing of increment formation in red throat emperor (Lethrinus miniatus) otoliths. Mar Freshw Res 56: $529-538$

Editorial responsibility: John Choat,

Townsville, Australia
Williams AJ, Mapstone BD, Davies CR (2006) Regional patterns in reproductive biology of Lethrinus miniatus on the Great Barrier Reef. Mar Freshw Res 57:403-414

Williams AJ, Mapstone BD, Davies CR (2007a) Spatial patterns in cohort-specific mortality of red throat emperor, Lethrinus miniatus, on the Great Barrier Reef. Fish Res 84: $328-337$

Williams AJ, Mapstone BD, Davies CR (2007b) Spatial and inter-annual patterns in growth of an exploited coral reef fish. J Fish Biol 71:970-992

Wolanski EJ (ed) (2001) Oceanographic processes of coral reefs: physical and biological links in the Great Barrier Reef. CRC Press, Boca Raton, FL

Zeller DC (1997) Home range and activity patterns of the coral trout Plectropomus leopardus (Serranidae). Mar Ecol Prog Ser 154:65-77

Zeller DC (1998) Spawning aggregations: patterns of movement of the coral trout Plectropomus leopardus (Serranidae) as determined by ultrasonic telemetry. Mar Ecol Prog Ser 162:253-263

Submitted: September 7, 2009; Accepted: February 3, 2010 Proofs received from author(s): April 23, 2010 